\title{
Research on Cooperative Emission Reduction Strategy for Supply Chain Considering Yield Uncertainty and Low Carbon Preference
}

\author{
Xueying Cao \\ School of Economics and Management \\ Guangxi University of Science and Technology \\ Liuzhou, China \\ 1204975209@qq.com
}

\author{
Zhigao Liao* \\ Department of Postgraduate Administration \\ Guangxi University of Science and Technology \\ Liuzhou, China \\ 46154910@qq.com
}

\author{
Lin Deng \\ School of Economics and Management \\ Guangxi University of Science and Technology \\ Liuzhou, China
}

\begin{abstract}
-under the carbon tax and government carbon emission reduction subsidy policy, a two-level supply chain cooperative emission reduction game model consisting of suppliers and manufacturers is constructed, where manufacturers are faced with yield uncertainty. The emission reduction decision of decentralized decision and the centralized decision is analyzed. It is proved that centralized decision is better than decentralized decision to realize Pareto improvement of supply chain. On this basis, three different cooperative emission reduction methods were proposed to explore the strategic selection of cooperative emission reduction in supply chain under uncertain production environment. The results show that the cost-sharing contract and profit-sharing contract cannot coordinate supply chain and yield uncertainty well. Cost-sharing and profit-sharing contracts can maximize the level of emission reduction and the profits of the whole supply chain and perfectly coordinate supply chain and yield uncertainty.
\end{abstract}

Keywords-yield uncertainty; Low carbon preference; Lowcarbon supply chain; Cost sharing; Profit sharing

\section{INTRODUCTION}

With the development of social economy, the emission of greenhouse gases has increased substantially. The greenhouse effect has a huge impact on the natural, social and ecological environment that human beings rely on for survival. The speed and extent of the impact have exceeded people's expectations. On the one hand, under the carbon emission trading scheme, enterprises must consider the cost of carbon emission when making production decisions. On the other hand, consumers are more inclined to buy low-carbon products [1], so enterprises must reduce carbon emissions to meet the needs of more and more consumers for low-carbon products. At the same time, the carbon emission reduction decisions of enterprises are not isolated. The carbon emission reduction decisions of enterprises upstream and downstream of the supply chain are closely related to the carbon emission reduction decisions of

This work is supported by the projects of Guangxi Philosophy and Social Science Project (17FJY007), Innovation Project of Guangxi Graduate

Education (YCSZ2014203) and National Social Science Fund Western Project (Project No.19XGL025) individual member enterprises in the supply chain. Only by considering from the perspective of the whole supply chain system can the ultimate carbon emission reduction target be achieved [2].

\section{LITERATURE REVIEW AND MOTIVATIONS}

At present, the supply chain cooperation emission reduction problem has become the focus of attention. Scholars at home and abroad have made in-depth research on this issue, and relevant research results keep emerging. Zhang et al. studied three models of supply chain $\mathrm{r} \& d$ without emission reduction, independent emission reduction $\mathrm{r} \& \mathrm{~d}$ and cooperative emission reduction $r \& d$ under the carbon tax policy, and found that the emission reduction of cooperative emission reduction $r \& d$ of supply chain is much lower than that of independent emission reduction $\mathrm{r} \& d$ [3]. Xinpeng Xie used the game theory to analyze the emission reduction effect, profit and social welfare of upstream and downstream enterprises under the conditions of non-cooperation, semi-cooperation and integrated cooperation [4]. With the deepening of the research, scholars closely combine the research content with the actual market environment to further enrich the research content. Hongjun Peng and Tao pang compared and analyzed the quantity discount contract and revenue sharing contract in the context of considering consumer preference judged the best scenario of cooperation between supply chain enterprises, and designed the revenue sharing contract considering emission reduction subsidies to better promote supply chain cooperation and arrangement [5].

With the gradual enhancement of consumers' awareness of environmental protection, consumers prefer eco-friendly goods and services. Hartikainen et al. show that the level of emission reduction of products usually has an impact on consumers[6]. While studying supply chain emission reduction decisions, scholars began to consider the low carbon preference of consumers. On the basis of considering consumers' preference for low carbon, Liu et al. studied the coordination of investment emission reduction contracts led by 


$$
\mathrm{p}=a-b q X+\lambda e
$$

Assumption 5: In order to curb the carbon emission of enterprises, the government imposes carbon tax Pt according to the final carbon emission of enterprises $\mathrm{e}_{0}$-e.At the same time, in order to alleviate the contradiction between enterprise emission reduction and profit, the government provides certain subsidies $t$ to the investment cost of enterprise emission reduction.

\section{B. Description of parameters and variable descriptors}

$\mathrm{a}, \mathrm{b}$ : $\mathrm{a}$ is the initial market price, and $\mathrm{b}$ is the impact coefficient of production on price;

$\mathrm{X}$ : Random yield, $\mathrm{E}(\mathrm{X})=1, \mathrm{D}(\mathrm{X})=\sigma^{2}$;

$\beta$ : Investment cost factor of emission reduction;

$\mathrm{C}_{\mathrm{s}}$ : Unit cost of raw materials;

$\mathrm{C}_{\mathrm{m}}$ : Manufacturing cost;

P: Product unit price;

$\mathrm{P}_{\mathrm{t}}$ : Carbon tax imposed by the government on carbon emission of manufacturers;

$\mathrm{e}_{0}$ : Initial carbon emission per unit product;

$\mathrm{t}$ : Subsidies given by the government to manufacturers;

$\pi_{\mathrm{s}}, \pi_{m}, \pi_{w}$ : Suppliers, manufacturers and overall supply chain profits;

$\lambda$ : Price sensitivity factor of emission reduction level;

e: Emission reduction per unit product;

q: Quantity of product;

w: Wholesale price of materials;

\section{ESTABLISHMENT AND SOLUTION OF THE MODEL}

We are considering a two-tier supply chain composed of suppliers and manufacturers, who are controlled enterprises and face output uncertainty. Suppliers determine wholesale prices for materials to maximize their profits. The manufacturer maximizes its profit by determining the order quantity and displacement reduction based on the known wholesale price. According to the Stackelberg method, we first consider the manufacturer's decision results.

\section{A. Optimal strategy of manufacturer under decentralized decision-making}

Under decentralized decision-making (represented by the upper standard D), according to the above description and hypothesis, we can obtain the manufacturer's profit:

$$
\pi_{\mathrm{m}}^{D}(\mathrm{q}, e)=p q X-\left(w+c_{m}\right) q-p_{t}\left(e_{0}-e\right) q-\frac{(1-t)}{2} \beta e^{2}, \quad t<1
$$

Since $\mathrm{p}=a-b q X+\lambda e$ and $E(X)=1, \operatorname{Var}(X)=\sigma^{2}$, we can get the manufacturer's expected profit is:

$$
E\left[\pi_{m}^{D}(q, e)\right]=\left(a-w-c_{m}+\lambda e\right) q-b q^{2}\left(1+\sigma^{2}\right)-p_{t}\left(e_{0}-e\right) q-\frac{1-t}{2} \beta e^{2}
$$

Theorem 1: in the case of decentralized decision-making, for any given wholesale price w, when $\left(\lambda+p_{t}\right)^{2}+2 b \beta\left(1+\sigma^{2}\right)(t-1)<0$, the manufacturer's optimal order quantity and carbon emission reduction level were calculated as follows:

$$
\mathrm{q}^{D^{*}}(w)=\frac{\beta(t-1)\left(a-c_{m}-e_{0} p_{t}-w\right)}{A}
$$

inversely proportional to price and consumers have a low carbon preference. Therefore, we assume that the inverse demand function is as follows: 


$$
\mathrm{e}^{D *}(w)=\frac{-\left(\lambda+p_{t}\right)\left(a-c_{m}-e_{0} p_{t}-w\right)}{A}
$$

where $A=2 b \beta\left(1+\sigma^{2}\right)(t-1)+\left(\lambda+p_{t}\right)^{2} ;$

\section{B. Optimal strategy of suppliers under decentralized decision-making}

We assume that the supplier produces no or very little carbon emissions in the production of raw materials, which can be ignored. Therefore, according to the above assumption, we can obtain the supplier's profit:

$$
\pi_{\mathrm{s}}^{D}(w)=\left(w-c_{s}\right) q
$$

Assume that the supplier determines the best wholesale price based on the manufacturer's decision:

$$
w^{D *}=\frac{a-c_{m}+c_{s}-e_{0} p_{t}}{2}
$$

Substitute(5) into (2)and(3) to obtain the optimal solution under decentralized decision- making, and the results are as follows:

$$
\mathrm{q}^{D *}=\frac{\beta(t-1) B}{2 A}, \mathrm{e}^{D *}=\frac{-\left(\lambda+p_{t}\right) B}{2 A}
$$

where $B=a-c_{m}-c_{s}-e_{0} p_{t}$

Substitute (5) and (6) into (1) and (4) to get:

$$
\begin{gathered}
\pi_{\mathrm{s}}^{D^{*}}=\frac{\beta(-1+\mathrm{t}) B^{2}}{4 A} \\
\pi_{\mathrm{m}}^{D^{*}}=E\left(\pi_{m}^{D^{*}}\right)=\frac{\beta(-1+\mathrm{t}) B^{2}}{8 A} \\
\pi_{\mathrm{w}}^{D^{*}}=E\left(\pi_{w}^{D^{*}}\right)=E\left(\pi_{\mathrm{s}}^{D^{*}}\right)+E\left(\pi_{m}^{D^{*}}\right)=\frac{3 \beta(-1+\mathrm{t}) B^{2}}{8 A}
\end{gathered}
$$

\section{Supply chain under centralized decision-making}

In the case of centralized decision-making (represented by the upper standard C), the optimal solution will give the maximum possible expected profit of the whole supply chain.

$$
\pi_{\mathrm{w}}^{C}(\mathrm{q}, e)=p q X-\left(c_{s}+c_{m}\right) q-p_{t}\left(e_{0}-e\right) q-\frac{(1-t)}{2} \beta e^{2}
$$

Similar to (1), we can get:

$$
E\left[\pi_{\mathrm{w}}^{C}(q, e)\right]=\left(a-c_{s}-c_{m}+\lambda e\right) q-b q^{2}\left(1+\sigma^{2}\right)-p_{t}\left(e_{0}-e\right) q-\frac{1-t}{2} \beta e^{2}
$$

Theorem 3: under the centralized decision, when $\left(\lambda+p_{t}\right)^{2}+2 b \beta\left(1+\sigma^{2}\right)(t-1)<0$, the calculation result of the optimal order quantity and carbon emission reduction level of the supply chain is as follows:

$$
\mathrm{q}^{C *}=\frac{\beta(t-1) B}{A}, \mathrm{e}^{C *}=\frac{-\left(\lambda+p_{t}\right) B}{A}
$$

where A and B are given in (2) and (5), respectively.

By substituting (11) into (10), the following equation can be obtained:

$$
\pi_{\mathrm{w}}^{C^{*}}=E\left(\pi_{w}^{C^{*}}\right)=\frac{\beta(\mathrm{t}-1) B^{2}}{2 A}
$$

Corollary $1: e^{C^{*}}>e^{D^{*}}, q^{C^{*}}>q^{D^{*}}, E\left(\pi_{w}^{C^{*}}\right)>E\left(\pi_{w}^{D^{*}}\right)$

Corollary 1 shows that the profit of supply chain under centralized decision is greater than that under decentralized decision, and the carbon emission reduction level under centralized decision is higher than that under decentralized decision, and the order quantity under centralized decision is greater than that under decentralized decision. This means that a company's carbon reduction will attract more consumers and increase consumer demand, thus increasing the company's profits.

\section{SUPPLY CHAIN COOPERATIVE EMISSION REDUCTION MODEL}

In this part, we will study cost sharing, profit sharing, and emission reduction cooperation scenarios under the dual incentive plan of cost sharing and profit sharing, and judge the optimal decision plan of low-carbon supply chain cooperative emission reduction by comparing supply chain profit and optimal emission reduction level in different scenarios.

\section{A. Cost-sharing contract}

In reality, as a systematic project, energy conservation and emission reduction need a large amount of capital as a guarantee. Therefore, under cost-sharing contracts (superscript CS), suppliers take the initiative to share a proportional share of the cost of emission reduction with manufacturers, and suppliers decide the wholesale price of materials to maximize their profits. The manufacturer maximizes its profit by determining the order quantity and displacement reduction based on the known wholesale price. According to the Stackelberg method, we first consider the manufacturer's decision results. The profit function model of supplier and manufacturer under cooperative $r \& d$ of supply chain emission reduction is

$$
\begin{aligned}
& \pi_{\mathrm{s}}^{C S}(w)=\left(w-c_{s}\right) q-\frac{(1-t)}{2} \theta \beta e^{2} \\
& \pi_{\mathrm{m}}^{C S}(\mathrm{q}, e)=p q X-\left(w+c_{m}\right) q-p_{t}\left(e_{0}-e\right) q-\frac{(1-t)}{2}(1-\theta) \beta e^{2}
\end{aligned}
$$

Similar to (1), we can get:

$$
E\left[\pi_{\mathrm{s}}^{C S}(w)\right]=\left(w-c_{s}\right) q-\frac{(1-t)}{2} \theta \beta e^{2}
$$

$E\left[\pi_{m}^{C S}(q, e)\right]=\left(a-w-c_{m}+\lambda e\right) q-b q^{2}\left(1+\sigma^{2}\right)-p_{t}\left(e_{0}-e\right) q-\frac{(1-t)}{2}(1-\theta) \beta e^{2}$

$E\left[\pi_{\mathrm{w}}^{C S}(q, e)\right]=\left(a-c_{s}-c_{m}+\lambda e\right) q-b q^{2}\left(1+\sigma^{2}\right)-p_{t}\left(e_{0}-e\right) q-\frac{1-t}{2} \beta e^{2}$

Theorem 5: in the cost-sharing cooperative emission reduction mode, when $2 \beta b(t-1)(\theta-1)\left(1+\sigma^{2}\right)>\left(\lambda+p_{t}\right)^{2}$, the results of the optimal order quantity and optimal emission reduction level are as follows:

$$
q^{C S *}=\frac{\beta(-1+t)(-1+\theta)^{2} B}{2 C+(2-3 \theta)\left(\lambda+p_{t}\right)^{2}}
$$




$$
\begin{aligned}
\pi_{w}^{C S^{*}} & =\frac{\beta(-1+t)(-1+\theta)^{2} B^{2}\left(3 C+(3-4 \theta)\left(\lambda+p_{t}\right)^{2}\right)}{2\left(2 C+(2-3 \theta)\left(\lambda+p_{t}\right)^{2}\right)^{2}} \\
C & =2 b \beta\left(1+\sigma^{2}\right)(-1+t)(-1+\theta)^{2}
\end{aligned}
$$

$$
\text { Corollary 2: } q^{C S^{*}}<q^{D^{*}}, e^{C S^{*}}<e^{D^{*}}, E\left(\pi^{C S^{*}}\right)<E\left(\pi^{D^{*}}\right)
$$

As $0<\theta<1$, under the cost-sharing contract, the optimal order quantity and the overall profit of the supply chain are both smaller than that under the decentralized decision, but the manufacturer has a higher emission reduction level. Thus, cost-sharing contracts not only fail to coordinate supply chains with uncertain output. This is mainly because suppliers can only spread the cost of emission reduction by raising the wholesale price, which reduces the final order quantity and the overall profit of the supply chain.

\section{B. Profit sharing contract}

Under the profit-sharing contract (superscript RS), the manufacturer buys raw materials from the supplier at a negotiated wholesale price and shares a certain percentage of the profits with the supplier to maximize the profits of the entire supply chain. In this process, the supplier does not have decision variables, and the manufacturer's decision variables are optimal order quantity and optimal emission reduction rate. Therefore, under the profit-sharing contract (superscript RS), the profit function model of suppliers and manufacturers under the cooperative research and development of supply chain emission reduction is as follows:

$$
\begin{aligned}
& \pi_{\mathrm{s}}^{R S}\left(w_{0}\right)=(1-\theta) p q X+\left(w_{0}-c_{s}\right) q \\
& \pi_{\mathrm{m}}^{R S}(\mathrm{q}, e)=\theta p q X-\left(w_{0}+c_{m}\right) q-p_{t}\left(e_{0}-e\right) q-\frac{(1-t)}{2} \beta e^{2}
\end{aligned}
$$

Similar to (1), we can get:

$$
\begin{aligned}
& E\left[\pi_{\mathrm{s}}^{R S}\right]=(1-\theta)\left[a \mathrm{q}+\lambda e q-b\left(1+\sigma^{2}\right) q^{2}\right]+\left(w_{0}-c_{s}\right) q \\
& E\left[\pi_{m}^{R S}(q, e)\right]=\theta\left[a q+\lambda e q-b q^{2}\left(1+\sigma^{2}\right)\right]-\left(w_{0}+c_{m}\right) q-p_{t}\left(e_{0}-e\right) q-\frac{(1-t)}{2} \beta e^{2} \\
& E\left[\pi_{\mathrm{w}}^{R S}(q, e)\right]=\left(a-c_{s}-c_{m}+\lambda e\right) q-b q^{2}\left(1+\sigma^{2}\right)-p_{t}\left(e_{0}-e\right) q-\frac{1-t}{2} \beta e^{2}
\end{aligned}
$$

Theorem 6: in the profit-sharing cooperative emission reduction mode, when $-2 b \beta \theta\left(1+\sigma^{2}\right)(t-1)-\left(\lambda \theta-p_{t}\right)^{2}>0$, the results of the optimal order quantity and optimal emission reduction level are as follows:

$$
\begin{array}{r}
q^{R S^{*}}=\frac{\beta(-1+t) B}{A-\lambda^{2}(\theta-1)^{2}} \\
e^{R S^{*}}=\frac{-\left(\lambda \theta+p_{t}\right) B}{A-\lambda^{2}(\theta-1)^{2}} \\
E\left(\pi_{w}^{R S *}\right)=\frac{\beta(-1+t) B^{2}}{2\left(A-\lambda^{2}(\theta-1)^{2}\right)}
\end{array}
$$

$$
\text { Corollary 3: } q^{R S^{*}}<q^{C^{*}}, e^{R S^{*}}<e^{C^{*}}, E\left(\pi^{R S^{*}}\right)<E\left(\pi^{C^{*}}\right)
$$

By comparing the (11),(12) and(23),(24) can be concluded that the quantity of goods, the reduction rate of profit sharing cooperation mode and the supply chain profits are less than the level of centralized decision-making scenarios, when $\theta=1$, profit sharing under the contract of equals profit under centralized decision making, but it does not exist in reality. Therefore, the profit sharing contract can increase the profit of the supply chain, but it is difficult to perfectly coordinate the supply chain with yield uncertainty.

\section{Cost sharing and profit sharing contract}

In order to better promote the cooperative emission reduction in the supply chain, it is assumed that the upstream and downstream enterprises of the supply chain carry out the dual incentive contract of cost sharing and profit sharing at the same time. Suppliers take the initiative to share the emission reduction cost of the manufacturer's proportion of $\theta$, and the manufacturer shares the income of the proportion of 1- $\theta$ to the supplier. In this process, the manufacturer chooses the best product order quantity and emission reduction to maximize its profit. With the profit sharing contract, we assume that the supplier does not have decision variables. Therefore, under the cost-sharing and profit-sharing contract (superscript BS), the profit function model of suppliers and manufacturers under the cooperative research and development of supply chain emission reduction is as follows:

$$
\begin{aligned}
& \pi_{\mathrm{s}}^{B S}\left(w_{0}\right)=(1-\theta) p q X+\left(w_{0}-c_{s}\right) q-\frac{(1-\mathrm{t})}{2} \theta \beta e^{2} \\
& \pi_{\mathrm{m}}^{B S}(\mathrm{q}, e)=\theta p q X-\left(w_{0}+c_{m}\right) q-p_{t}\left(e_{0}-e\right) q-\frac{(1-t)}{2}(1-\theta) \beta e^{2}
\end{aligned}
$$

Similar to (1), we can get:

$$
\begin{aligned}
& E\left[\pi_{\mathrm{s}}^{B S}\right]=(1-\theta)\left[a \mathrm{q}+\lambda e q-b\left(1+\sigma^{2}\right) q^{2}\right]+\left(w_{0}-c_{s}\right) q-\frac{(1-t)}{2} \theta \beta e^{2} \\
& E\left[\pi_{m}^{B S}(q, e)\right]=\theta\left[a q+\lambda e q-b q^{2}\left(1+\sigma^{2}\right)\right]-\left(w_{0}+c_{m}\right) q-p_{t}\left(e_{0}-e\right) q-\frac{(1-t)}{2}(1-\theta) \beta e^{2} \\
& E\left[\pi_{\mathrm{w}}^{B S}(q, e)\right]=\left(a-c_{s}-c_{m}+\lambda e\right) q-b q^{2}\left(1+\sigma^{2}\right)-p_{t}\left(e_{0}-e\right) q-\frac{1-t}{2} \beta e^{2}
\end{aligned}
$$

Theorem 7: in the cost-sharing and profit-sharing cooperative emission reduction mode, when $2 b \beta \theta\left(1+\sigma^{2}\right)(-1+t)(-1+\theta)-\left(\lambda \theta+p_{t}\right)^{2}>0$, the results of the optimal order quantity and optimal emission reduction level are as follows:

$$
\begin{aligned}
q^{B S *} & =\frac{\beta(-1+t)(-1+\theta)^{2} B}{C+\lambda^{2}(2-3 \theta) \theta-2 \lambda\left(-1+\theta+\theta^{2}\right) p_{t}+(1-2 \theta) p_{t}{ }^{2}} \\
e^{B S *} & =\frac{-(-1+\theta)\left(\lambda \theta+p_{t}\right) B}{-C+\lambda^{2} \theta(-2+3 \theta)+2 \lambda\left(-1+\theta+\theta^{2}\right) p_{t}+(-1+2 \theta) p_{t}{ }^{2}} \\
\pi_{w}^{B S} & =\frac{\beta(-1+t)(-1+\theta)^{2} B^{2}}{2\left(C+\lambda^{2}(2-3 \theta) \theta-2 \lambda\left(-1+\theta+\theta^{2}\right) p_{t}+(1-2 \theta) p_{t}{ }^{2}\right)}
\end{aligned}
$$

Corollary 4: when $0<\quad \theta<1, \quad E\left(\pi_{\mathrm{m}}^{B S^{*}}\right)=\theta E\left(\pi_{w}^{B S^{*}}\right)$, $E\left(\pi_{\mathrm{s}}^{B S^{*}}\right)=(1-\theta) E\left(\pi_{w}^{B S^{*}}\right)$ 


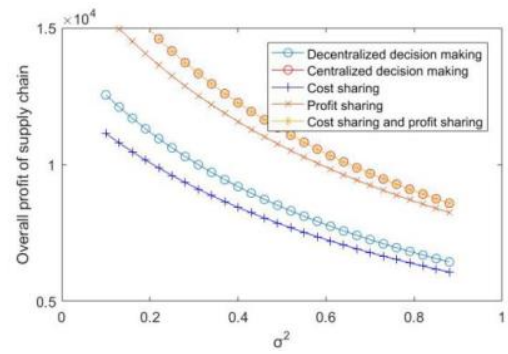

This shows that cost-sharing and profit-sharing contracts can perfectly coordinate output uncertainty and supply chain. Under the dual incentive factors, the manufacturer's emission reduction rate and the overall profit of the supply chain will reach the level of centralized decision-making.

\section{ANALYSIS OF EXAMPLES}

In order to more directly reflect the impact of production uncertainty and consumers' low-carbon preference on lowcarbon supply chain under different ways of sharing and cooperation, the rationality and effectiveness of the model were verified. The basic parameters were set as follows:

$\mathrm{a}=900, \mathrm{~b}=9, \mathrm{c}_{\mathrm{s}}=180, \mathrm{c}_{\mathrm{m}}=40, \beta=140, \mathrm{e}_{0}=20, \mathrm{p}_{\mathrm{t}}=0.4, \mathrm{t}=0.5, \theta=0.5, \lambda$ $=18, \sigma^{2}=0.3, \theta=0.5$

From Fig.1 to Fig.4, we can draw the following conclusions:

(1) Uncertainty of output has a negative impact on profit and emission reduction level of the supply chain, while consumers' preference for low carbon has a positive impact on .54profit and emission reduction level of the supply chain.

(2) $\pi^{C}=\pi^{B C}>\pi^{R S}>\pi^{D}>\pi^{C S}$

$$
\mathrm{e}^{B C}=e^{C}=e^{C S}>e^{D}>e^{R S}
$$

In the uncertain environment of output, the profit level of the supply chain under the cost-sharing and profit-sharing contract is the same as that under the centralized decisionmaking, and the cost-sharing and profit-sharing contract can promote the emission reduction to reach the level under the centralized decision-making. Profit sharing contract can improve the profit of supply chain to some extent, but it can't reach the profit level under the centralized scenario. This is mainly because under the profit-sharing contract, the cost of emission reduction is borne by the manufacturer alone, while the increased profit of consumers' low-carbon preference is Shared with suppliers, which inhibits the manufacturer's initiative to reduce emission. The cost-sharing contract can improve the emission reduction level of manufacturers but cannot improve the overall profit of the supply chain. This is because after suppliers share the emission reduction cost, it is difficult to disperse the emission reduction cost, which increases the wholesale price of raw materials and reduces the profit of the whole supply chain.

(3) From the above conclusion, it can be seen that under the dual incentive factors of cost sharing and profit sharing, the profit and emission reduction of the supply chain can reach the level of centralized decision-making and coordinate the uncertainty of supply chain and output well. However, profit sharing contract and cost sharing contract cannot well coordinate the profit, emission reduction level and output uncertainty environment of the supply chain.
Fig.1. The impact of $\sigma 2$ on the profitability of the supply chain

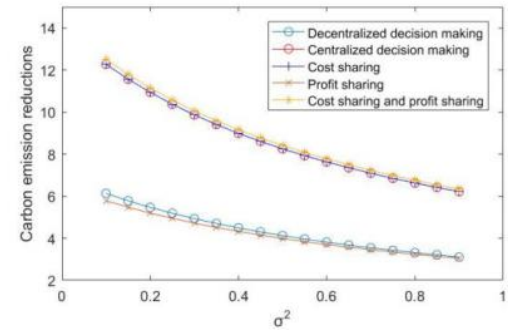

Fig.2. The impact of $\sigma^{2}$ on carbon emission reduction

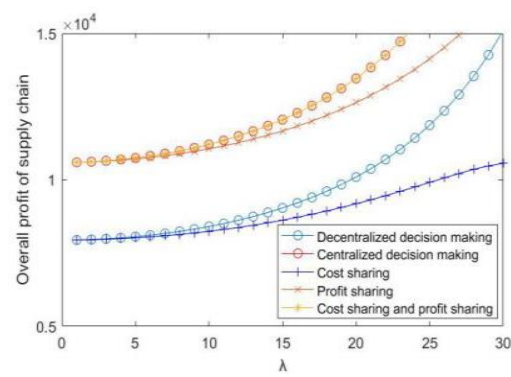

Fig.3. The impact of $\lambda$ on the profitability of the supply chain

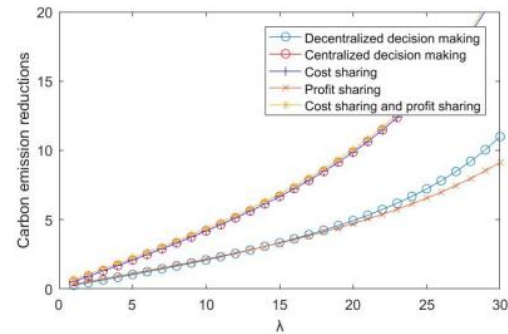

Fig.4. The impact of $\lambda$ on carbon emission reduction

\section{CONCLUSIONS}

For consumers with preference of low carbon output uncertain market, in the case of a carbon tax policy and subsidies to reduce emissions, emissions through the supply chain cooperation game model is analyzed, found that allows manufacturers to reduce emissions levels increase cost sharing contract but will reduce the overall supply chain profit, unable to coordinate the supply chain uncertainty and yield, mainly because the supplier can only by raising the increased cost of raw materials wholesale prices to disperse, make the whole supply chain profit decrease. Profit sharing contract can improve the profit and emission reduction level of the supply chain, but it cannot reach the level of centralized decisionmaking, and cannot perfectly coordinate the uncertain supply 
[2] You L, Xin X, Gang Y. Research on cooperative emission reduction decision-making mechanism of supply chain enterprises under two kinds of split contracts [J].China management science, 2016, 24(03):61-70.(In Chinese)

bears the cost of emission reduction alone, and the profit increased by emission reduction needs to be shared with the supplier, which inhibits the enthusiasm of the manufacturer to reduce emission. Cost-sharing and profit-sharing contract can make the manufacturer's emission reduction level and supply chain profit reach the centralized decision-making level, and perfectly coordinate the supply chain and output uncertainty. Therefore, when enterprises are faced with uncertain output environment, they should choose the double incentive plan of cost sharing and profit sharing to realize the cooperative emission reduction of supply chain.

\section{REFERENCES}

[1] Jia S, Zhong X. Research on low-carbon supply chain emission reduction strategy considering consumers' double preference [J].Chinese management science, 2018, 26(04):49-56.(In Chinese)

[3] Han Z, Jia Z, Ming L. Game analysis of government behavior and supply chain cooperative research and development in the context of low carbon [J].Chinese management science, 2015, 23(10):57-66.(In Chinese)

[4] Xin X, Dao Z. Research on cooperation strategies of low-carbon supply chain enterprises in emission reduction [J].Management science, 2013, 26(03):108-119.(In Chinese)

[5] Peng H, Pang T, Cong J. Coordination contracts for a supply chain with yield uncertainty and low-carbon preference [J].Journal of Cleaner Production, 2018: 291-302.

[6] Hartikainen H, Roininen T, Katajajuuri J, et al. Finnish consumer perceptions of carbon footprints and carbon labeling of food products[J].Journal of Cleaner Production, 2014: 285-293.

[7] Dao Z, Bai Y, Chun X. Dynamic coordination strategy of vertical emission reduction cooperation in supply chain under low-carbon environment [J]. Journal of management engineering, 2016, 30(01):147154. (In Chinese) 